This is the author's final, peer-reviewed manuscript as accepted for publication. The publisher-formatted version may be available through the publisher's web site or your institution's library.

\title{
Community marriage initiatives
}

William J. Doherty and Jared R. Anderson

\section{How to cite this manuscript}

If you make reference to this version of the manuscript, use the following information:

Doherty, W. J., \& Anderson, J. R. (2004). Community marriage initiatives. Retrieved from http://krex.ksu.edu

\section{Published Version Information}

Citation: Doherty, W. J., \& Anderson, J. R. (2004). Community marriage initiatives. Family Relations, 53(5), 425-432.

Digital Object Identifier (DOI): doi:10.1111/j.0197-6664.2004.00050.x

\section{Publisher's Link:}

http://onlinelibrary.wiley.com/doi/10.1111/j.0197-6664.2004.00050.x/full 


\author{
Community Marriage Initiatives \\ William J. Doherty and Jared R. Anderson \\ University of Minnesota
}

William J. Doherty, Ph.D., Professor, Department of Family Social Science, University of Minnesota; Jared R. Anderson, M.S., Doctoral Student, Department of Family Social Science, University of Minnesota.

Address correspondence to: William J. Doherty, Department of Family Social Science, University of Minnesota, 290 McNeal Hall, St. Paul, MN 55108; e-mail: bdoherty@che.umn.edu 


\begin{abstract}
This article reviews the development of community marriage initiatives and their relationship with family professionals, with particular emphasis on sociohistorical context. We describe five leading community marriage initiatives, discuss the state of the evaluation research, and propose new directions for this promising area of work.
\end{abstract}

Keywords: marriage, marriage education, community, evaluation 


\section{Community Marriage Initiatives}

For more than three decades there has been a not-always-comfortable relationship between marriage professionals and lay-led community initiatives. This article reviews this history of community marriage initiatives, with an emphasis on the historical and cultural context, then describes five exemplar community marriage initiatives, discusses key issues in their implementation and evaluation, and proposes next steps for partnership between professionals and community leaders in creating community initiatives to promote healthy marriages. We deal only tangentially with the important parallel developments of couples skills programs developed and researched by academics and other professionals (Halford, Markman, Kline \& Stanley, 2003).

Since the field is relatively new and has not been subject to historical inquiry, this article represents only one perspective on this history and current developments, albeit one informed by three decades of "participant observation” by the first author. Some observers no doubt would frame the developments in community marriage initiatives as stemming primarily from the translating of academic findings on relationship skills to the field (Stanley, Markman, St. Peters, \& Leber, 1995), whereas our perspective emphasizes broader social and cultural forces and assigns a secondary role to the work of academics and family professionals.

The 1970s marked the initial flourishing of marriage programs featuring coupleto-couple support as distinguished from professional counseling. In 1973, family professionals David and Vera Mace founded the Association for Couples in Marriage Enrichment (ACME), in hopes of creating an umbrella organization for all couple-based initiatives in marriage enrichment (Mace, 1983). Their larger goal was not realized, but 
their organization did launch couple support groups not tied to professional services or curricula that continue in many parts of the country. By far the largest non-professional movement of the 1970s was Marriage Encounter, which had spread to the U.S. from Spain. Hundreds of thousands of couples, mostly Catholic but also from other denominations, attended weekend retreat programs led by a clergyperson and two lay couples, the aim of which was marital renewal in the context of spiritual renewal (Elin, 1999). Marriage Encounter, which explicitly avoided interacting with marriage and family professionals, attracted concerns from marital therapists and academics about the potential risks of its intensive format for distressed couples (Lester \& Doherty, 1983). But by the late 1970s, the promise of lay-led, community-based marriage programs seemed enormous.

In the 1980s the mass market for marriage enrichment went flat. Marriage Encounter weekend retreats dwindled and faith communities seemed to turn their attention elsewhere. Many professionals found they could not fill their skills courses. Only programs for premarital couples such as PREPARE (Olson \& Olson, 1999) and Catholic Pre-Cana continued to attract large and growing numbers of couples, in part because they had audiences who were required to participate. It is also important to note that the 1980s were an incubation period for important academic research on couples skills programs, and that a number of currently prominent couples programs such as PREP (Stanley, Blumberg, \& Markman, 1999), Relationship Enhancement (Cavedo \& Guerney, 1999), Couples Communication (Miller \& Sherrard, 1999), and PAIRS (Gordon \& Durana, 1999) continued to develop during this period. But in our observation 
the reach of these professional programs paled in comparison with the huge public response to Marriage Encounter and related church programs of the 1970s.

Looking back at this turnaround, it is now clear how much the 1970s marriage “enrichment” movement was fed by the human potential movement. During the 1980s, the mainstream culture's fascination with personal growth faded as the consumer culture blossomed (Cohen, 2003). What's more, the political climate of the Reagan era deemphasized funding for the prevention of mental health and family problems; the medical model and pharmaceutical solutions prevailed. "Marital therapy" became the new name for “marriage counseling” (Fancher, 1995). Marriage and family therapists competed for recognition as bonafide mental health treatment providers for insurance panels and employee assistance programs (Shumway, Wampler, Dersch, \& Arredondo, 2004). In this environment, many therapists abandoned whatever interest they had in prevention and enrichment, which were not reimbursable.

On top of these developments, the 1980s brought the feminist critique of marriage into the family field, and many researchers and professionals began to emphasize only the dark side of marriage (Blaisure \& Allen, 1995). Mainstream ideology moved from embracing the value of marriage towards a neutral or even skeptical view of marriage as just one form of adult partnership alongside cohabitation, with married couple families seen as not necessarily superior to one-parent families (Doherty \& Carroll, 2002a). Many religious leaders from mainstream denominations developed the same ambivalence about marriage as they struggled over how to support couples without accepting traditional patriarchal norms or disparaging other family forms (see Browning et al.'s, 2000, landmark book “From Culture Wars to Common Ground”). By the end of the 1980s, 
when the divorce rate was ebbing, there seemed to be growing awareness among professionals and academics that unstable marriage was a reality to be dealt with (Stacey, 1990). However, what was known as “marriage enrichment” seemed a bit antiquated, and social, cultural, professional, and religious energies were in other places than the marriage arena.

The first half of the 1990s was mostly a continuation of the 1980s retreat. The established marriage programs, both professional and community-based, limped along in terms of widespread public awareness although not in terms of important educational and research developments (for research developments, see Stanley et al., 1995). One professional pioneer confessed that he did not know of anyone in the United States who made a full time living from marriage enrichment. Only the premarital programs continued to flourish with high numbers of couples in the 1990s, although still reaching only a small fraction of marrying couples.

But the seeds of a renewal of marriage were germinating by mid-decade, fed by broader cultural change. A widespread revisiting of the divorce revolution surfaced in mid-decade. Barbara Dafoe Whitehead's (1993) article on divorce and two parent families in the politically progressive magazine The Atlantic Monthly lit the spark. Its provocative title: “Dan Quayle Was Right.” (The Vice President had criticized a television show for glamorizing father-absent single parent families.) The controversy was intense, which indicated that a new cultural and professional dialogue had arrived.

In 1995, Diane Sollee, a marriage and family therapist, coined the term “marriage education” (as a replacement for “marriage enrichment” or “psychoeducation”) and founded the Coalition for Marriage, Family, and Couples Education, with the goal of 
connecting the disparate marriage education groups and jump-starting a movement to foster healthy marriages through education and cultural change. She created a national clearinghouse for marriage information, began an annual national conference, generated intense media attention, and galvanized public policy, professional, and community interest in skills-based education for marriage in schools, churches, extension offices, military bases, child birth classes and a variety of other settings. Within the first five years, attendance at Sollee’s Smart Marriages conferences grew from 400 to 1,100. By 2003, the figure reached 1,800 at a time when other conferences were stable or declining in participants. Her smartmarriages.com list serve continues to provide a steady flow of information on marriage and marriage initiatives to thousands of subscribers. Starting in 1995, a revived marriage education movement began to coalesce, this time with closer collaboration between professionals and lay people in communities.

During the same period of the mid to late 1990s, religious leaders were beginning to respond to calls by individuals such as journalist Michael McManus to assert leadership in preventing divorce and salvaging marriages. McManus began to travel the country promoting a “Community Marriage Policy” in which clergy would agree to not perform weddings unless couples had gone through an extended premarital education experience (McManus, 1995, 2003a). Many clergy groups signed on. McManus also developed a program called “Marriage Savers," in which church groups develop mentoring programs for couples at various stages of the marital life cycle, and in various states of marital health (McManus, 2003b). These couple-to-couple mentor programs represented a major new type of marriage education, the first new modality of intervention we are aware of since the 1970s. 
By the early years of the $21^{\text {st }}$ century, marriage education clearly had transcended its dual roots (professional and church-based) into the arena of broader community coalitions. The prime impetus for this revival, in our view, has not been mainstream family professionals, many of whom remain ambivalent about marriage as a social institution, emphasize the equivalence of cohabiting unions, fear the denigration of single parent families, and worry about the exclusion of gay couples (Pinsof, 2002). Furthermore, with some exceptions such as Stanley et al. (2001), most family professionals are not accustomed to community building and forging alliances with nonprofessionals (Doherty \& Carroll, 2002b). Instead, the current energy and impetus for change comes from the growing marriage movement which can be seen as a widespread cultural trend, at multiple levels and with various constituencies, to revive the institution of marriage. Think tanks are also devoting their energies to marriage (notably David Blankenhorn’s Institute for American Values; David Popenoe’s and Barbara Dafoe Whitehead’s National Marriage Project; and Theodora Oom’s Marriage Project within the Center for Law and Social Policy).

In the public sector, state legislatures and governors are getting involved in initiatives to support premarital education, covenant marriage, and relationship education in high schools (See Brotherson \& Duncan, this issue). States such as Oklahoma are using TANF (welfare) surplus funds for marriage education at the community level. The federal government is funding community healthy marriage initiatives with a special focus on low-income couples (See Ooms \& Wilson, this issue). In November 2000, religious bodies from Roman Catholic, Southern Baptist and the evangelic National Council of Churches in Christ jointly declared their support for reviving marriage and 
preventing divorce (Murphy, 2000). There are stirrings of a movement in the AfricanAmerican community to restore marriage to a position it held in the past (Franklin, in press). Even the current debate about gay marriage can be seen as an indicator of strong contemporary interest in marriage as a social institution so important that a new group wants entry. Another symbol of changing cultural times was the wedding of feminist Gloria Steinam in 2000. In extemporaneous remarks before a presentation to family therapists, she remarked that she was bringing the news that getting married can be a radical countercultural act, and that she used to see marriage as "limiting," but now she sees having someone in your corner for life as “limitless” (authors’ notes from Steinam’s keynote address at the Psychotherapy Networker Conference, March 2001).

Tied to this rising marriage movement, the field of marriage education has experienced a remarkable renaissance since 1995, with community initiatives at the forefront of the action. Unlike the 1970s, a number of family professionals are partners, not skeptical outsiders, in many community marriage initiatives, although family professionals who ally themselves with the marriage movement are sometimes viewed with skepticism by their colleagues (Doherty \& Carroll, 2002a). For this article, we have chosen as exemplars five of the most ambitious community initiatives, although new ones are starting up every month.

\section{Examples of Community Marriage Initiatives}

The community marriage initiatives described here have several things in common. Each began as a reaction to the perceived breakdown of marriages and families at local and national levels. Dramatic increases in divorce, cohabitation, and non-marital childbearing over the past thirty years, along with declining rates of marriage, stirred 
community leaders to action (e.g., McManus, 1995, Murphy, 2000). Each community marriage initiative includes stakeholders from various sectors of the community (business, government, clergy, and education —-with faith communities frequently taking the lead role [see Stanley et al., 1995]). And each initiative has what is variously called a “Community Marriage Policy,” a “Community Marriage Covenant,” or a “Marriage and Family Agreement.” These are informal agreements signed by clergy that set minimum guidelines for the preparation and education of engaged couples. The guidelines are developed locally and therefore are not uniform across communities, but they generally require taking a premarital inventory in conjunction with 4-6 sessions of mandatory premarital counseling in order to formalize, standardize, and add rigor to the preparation process. Following are brief overviews of five community marriage initiatives selected because they have the longest track records and have achieved national visibility.

\section{Marriage Savers}

Marriage Savers, founded in 1996 by Mike and Harriet McManus, is a national organization that assists churches in strengthening marriages. Although Marriage Savers, as a formal organization, has been in existence since 1996, the McManus' have been promoting the establishment of Community Marriage Policies (CMPs) across the country since 1986, when Modesto, California became the first city to adopt a CMP. Marriage Savers is not a community initiative itself but works with local communities across the country to develop grass roots movements to support and encourage healthy marriages. Marriage Savers has also been instrumental in the initial development of other community marriage initiatives such as Healthy Marriages Grand Rapids, Families Northwest, and First Things First. Marriage Savers has two primary components, 
establishing CMPs and developing Marriage Saver Congregations. Approximately 6,000 clergy in over 175 cities across the country have signed a CMP.

A church becomes a "Marriage Saver" congregation by training mentor couples to work with engaged and young married couples, and by developing programs for couples and families to promote marriage enrichment, reconciliation of troubled marriages, and support groups for step-families (Marriage Savers, n.d.). The training of seasoned mentor couples to "walk along side" engaged and newlywed couples is a key component of the Marriage Savers model, but one that subsequent groups who have adopted CMPs have not always implemented. Mentor couples considered to be in a vital, long-term marriage (15-50 years married) are selected by local pastors to take part in the McManus' two day, 12 hour mentor couple training. The training prepares the mentor couple to administer and discuss the results of a premarital inventory with the mentored couple and to engage the couple in communication and conflict resolution exercises (McManus, 2003a). To reconcile troubled marriages "back from the brink" couples are recruited and trained to mentor couples currently in distressed marriages. The mentor couple shares how they turned their marriage around and leads the mentored couple through 17 "Marriage Ministry Action Steps”, a process similar to the 12-step Alcoholics Anonymous model (McManus, 2003b).

Although there are anecdotal reports that almost all troubled marriages can be saved by such mentoring (McManus, 2003b), the mentoring process has not been empirically tested. It is also important to note that almost everyone in the field believes that not all marriages can or should be saved. Therefore, programs engaging in lay-led 
mentoring of troubled marriages should include sufficient training on when to appropriately refer and when "saving the marriage" may not be indicated.

A controversial aspect of Marriage Savers has been McManus's claim that CMPs have reduced divorce rates substantially in the communities that have implemented them. In 2002, Marriage Savers hired the Institute for Research and Evaluation to assess the effect that adopting a CMP has had on divorce rates in these communities (McManus, 2002). The final report (Birch, Weed \& Olson, this issue) offers evidence of a positive effect of CMPs on divorce rates in counties that adopted them compared to carefully matched non-participating counties. While there are important limitations in this research because of lack of data on how the elements of CMPs were actually implemented in the participating communities, the study gives the first scientific support for the possible efficacy of community marriage initiatives.

\section{Healthy Marriages Grand Rapids}

Healthy Marriages Grand Rapids (HMGR), originally known as the Greater Grand Rapids Community Marriage Policy, began as a community initiative in 1997 "to encourage and empower couples for lifelong healthy marriages, and to raise the standard of two parent families in the community” (Healthy Marriages Grand Rapids, n.d.a, para. 1). To accomplish these goals, HMGR promotes the signing of CMPs, offers a variety of community programs, and generates public awareness through the media (Healthy Marriages Grand Rapids, n.d.a).

In addition to promoting the signing of CMPs, HMGR sponsors premarital workshops in both faith-based and civil settings, trains pastors and lay leaders (nearly 300) to administer premarital inventories, hosts events specifically focused on marriage 
and enrichment issues in the African American community, and has designated February as “Celebrate Marriage Month" to raise awareness in the community about the importance of marriage. In collaboration with Calvin College, HMGR has completed several research projects to understand the attitudes and values that community members have of marriage, to determine the trends in divorce, marriage, and unwed pregnancy rates, and to identify the resources within the community that are involved in supporting marriage. Research studies are beginning to evaluate the effectiveness of these interventions and programs (Healthy Marriages Grand Rapids, n.d.b).

In May of 2003, HMGR in collaboration with two other local agencies was awarded a \$990,000 federal grant approved by the state of Michigan to embark on a fiveyear demonstration project to improve child support enforcement and the financial well being of low-income families. An additional focus of the project will be to infuse healthy marriage/relationship programs into already existing services provided by the collaborating agencies. This will enable low-income couples to have better access to marriage preparation classes, premarital inventories, and relationship skills courses (Healthy Marriages Grand Rapids, 2003). The federal dollars represent additional funding to the state and does not affect the funding of already established child support programs. In addition, in order to secure the federal dollars, the collaborating agencies must raise $\$ 500,000$ in matching dollars from foundations, private donations, or through corporate sponsors.

\section{Families Northwest}

Families Northwest (FNW), founded in 1996, is a statewide organization in Washington (recently extended to Oregon) working to improve the success rate of 
marriage, decrease the divorce rate and improve the health of marriages and families. FNW provides educational resources and training services to individuals, families, and communities to help them develop marriage initiatives throughout the state of Washington (Families Northwest, n.d.). In 2002 FNW developed "Strategy Blueprints,” which describes the initiatives that will be part of their four-phased, ten-year "cultural campaign.” The centerpiece of phase one is the "Marriage and Family Agreements" (MFAs). Over 700 churches in 175 cities and towns have signed a MFA. In phase one FNW also works to provide pastors with the latest research information on marriage and family issues and to connect them to resources that will assist them in implementing educational and preparatory programs for marriages across the life cycle as a part of a community wide strategy to strengthen marriage (Krafsky, n.d.).

Phases II-IV (Winter 2003-2012) will focus on informing and enlisting public support for the marriage initiatives with the goal of creating a marriage culture in each community where marriage is honored and the community is engaged in strengthening marriages and families. FNW sponsors a daily one-minute radio feature, a bi-monthly newsletter, a weekly online family news update, and consults with communities in states across the country that are attempting to start community marriage initiatives. Research projects completed by FNW have examined the marriage attitudes and behaviors of Washington residents and the attitudes and activities that influence their family time. FNW intends to be involved in longitudinal quantitative and qualitative research in collaboration with local universities and colleges to determine initiative effectiveness (Krafsky, n.d.). 


\section{First Things First}

First Things First (FTF) is a non-profit organization that began in 1997 in Chattanooga, Tennessee. Local leaders joined together to start a community initiative to "rebuild, renew, and revitalize our city, beginning with the family" (First Things First, n.d.a, para. 3). FTF has been involved in many projects and programs to strengthen families in the Chattanooga area. FTF helped to establish the Hamilton County Divorce Education and Mediation Pilot Project, launched fathering and marriage Public Service Campaigns, trained hundreds of professionals through marriage enrichment, stepfamily strengthening, fathering and parenting seminars, and in 1998 conducted a Fathering Summit. FTF sponsors premarital classes, an African American marriage celebration weekend, and is involved in promoting family friendly policies in area businesses. Along with Marriage Savers, FTF recruits local churches to sign a Community Marriage Covenant. (First Things First, n.d.a).

Through these programs and activities FTF aims to reduce the divorce rate and out of wedlock pregnancy rate by $30 \%$ in Hamilton County (Chattanooga). FTF also hopes to strengthen marriages and increase father involvement with their children (First Things First, n.d.a). As a community healthy marriage initiative, FTF is both a template and a training ground for the development of additional initiatives across the country. The Administration for Children and Families has brought interested leaders from around the country to Chattanooga to provide training in the FTF model. In 1999 FTF issued a report describing the marriage, divorce, and cohabitation rates and attitudes of Hamilton County residents in order to provide a baseline of behaviors and attitudes from which subsequent 
research could determine the effectiveness of the community interventions (First Things

First, n.d.b).

Oklahoma Marriage Initiative

The Oklahoma Marriage Initiative (OMI) was launched in 1999 when then

Governor Frank Keating earmarked ten million TANF surplus dollars to support marriage initiatives. The impetus was a state economic report that showed that social indicators such as high divorce rates had a negative effect on the economy (Johnson et al., 2002). The OMI was established as a “multi-sector strategy” dedicated to reducing the state’s divorce rate and to strengthening families (Oklahoma Marriage Initiative, n.d.a). The goal of the OMI is to reduce the divorce rate in the state of Oklahoma by one third by 2010. In the fall of 2001 a landmark survey of the attitudes of Oklahomans about marriage, divorce, cohabitation, and marriage education was conducted. Leading researchers from around the country served as consultants to assist in the design and completion of the survey. The survey is beginning to be used by other states with the goal of establishing a national comparative database. The study will serve as a baseline to determine the progress toward reducing the divorce rate, understanding how the programs affect the attitudes of the people in the state, and tailoring the programs to the needs of the people (Johnson et al., 2002).

The central component of the OMI is to provide marriage and relationship education skills to couples. The Prevention and Relationship Enhancement Program (PREP), an empirically based, skill building marriage/relationship education approach was the program chosen to be offered throughout Oklahoma. PREP seeks to reduce risk factors associated with marital failure by teaching couples communication and conflict 
resolution strategies and helping couples clarify and evaluate their relationship expectations. PREP also attempts to raise protective factors that are associated with marital success by increasing a couple’s understanding of commitment and enhancing their relationship through fun, friendship, and sensuality (Markman, Stanley \& Blumberg, 1994; Stanley et al., 1999; Stanley et al., 1995). Community service providers (including church lay leaders and therapists) and "frontline staff" (from agencies such as the Department of Human Services, Health Department, Cooperative Extension) participate in a three-day training workshop in order to be designated county workshop leaders. The frontline staff will include these workshops in their agency curriculum and the community service providers have agreed to conduct the PREP workshops free of charge in their counties four times during the calendar year following their free training. Other agency and program staff throughout the state are being educated about the OMI and how to refer people to the free county-based PREP workshops (Oklahoma Marriage Initiative, n.d.b). Finally, the OMI has partnered with faith communities to sign the Oklahoma Marriage Covenant a community level agreement about premarital preparation and education similar in purpose to "Community Marriage Policies” and "Marriage and Family Agreements.” The OMI in collaboration with the Oklahoma State University Bureau for Social Research will be involved in ongoing evaluative research to measure the effectiveness of the statewide initiative (Johnson et al., 2002).

As community marriage initiatives continue to emerge around the country and as federal money is set aside to fund some of these initiatives, there will be increased scrutiny from outside groups as well as academics. It will be critical that community marriage initiatives develop and implement comprehensive evaluation plans to determine 
their effectiveness. Fortunately, there is a growing research literature from fields such as public health and education on how to assess community initiatives. We draw on this literature in the next section.

Issues in Implementation and Evaluation

The implementation and evaluation of community initiatives can be a complex and daunting task. Unlike agency programs that are often time-limited and specific to a narrow population, community initiatives generally develop to tackle intricate problems through diverse, multifaceted solutions. Although community initiatives have commonalities, their designs, interventions, and programming tend to be local, specific and contextual. Therefore, there are no “one size fits all” approaches to implementation and evaluation. Both are dependent on the needs of the targeted population, the resources available and the expectations of important stakeholders (Goodman, 1998; Israel et al., 1995).

The key to both implementation and evaluation is having a clear theory of action, sometimes called a program theory or logic model (Goodman, 1998). A theory of action specifies the problem(s) being addressed, the interventions necessary to address them, and the expected outcomes that will result from intervention. Although all programs have implicit theories underlying their initiatives, less frequently are these theories explicitly used to guide program development. An explicit theory of action clarifies the assumptions underlying program interventions and guides implementation by defining the intervention procedures (Goodman, 1998; Rossi, Freeman, \& Lipsey, 1999).

A theory of action also guides evaluation. Evaluation determines if the programs and initiatives make a difference in the lives of the people they serve and if they were 
implemented as designed (Royse, Thyer, Padgett, \& Logan, 2001). In an increasingly competitive funding market, where money is tied to performance, only those programs that prove to be effective will be competitive in gaining financial support. Evaluations are also necessary to gauge participant satisfaction, to refine and revise the programs, and to understand how the programs work "on the ground" so that if successful, they can be implemented in other communities (Rossi et al., 1999; Royse et al., 2001).

Although evaluations will differ depending on the context and questions asked, a strong evaluation will include an assessment of how the program is being implemented (process) and how the program interventions affect targeted social outcomes (impact and outcome). These results can then support the underlying program theory or help to refine the program (Rossi et al., 1999; Royse et al., 2001). Until recently, approaches to program evaluation primarily stressed impact or outcome evaluations (Israel et al., 1995). But most researchers now agree that process evaluations are vital to any comprehensive program evaluation (Rossi et al., 1999; Royse et al., 2001). Process evaluations involve a thorough analysis of the implementation process and assist in the interpretation of outcome data. Process evaluations enable researchers to understand why their program was effective and whether program theory or poor implementation was behind a program's ineffectiveness. Process evaluations can come in many forms, both qualitative and quantitative, and can include tools such as surveys or in depth interviews. For more information on the specifics of conducting process evaluations, see Dion et al., 2003; the Lewin Group, 1996; McGraw et al., 1994; Rossi et al., 1999; and Royse et al., 2001.

Contemporary outcome research on community initiatives focus on the effects of interventions on targeted social problems, not just effects on individuals. Just as process 
research has gained in importance over the past twenty years, so has the idea that evaluators need to broaden the types of outcomes they measure and that intermediate outcomes (sometimes referred to as proximal outcomes or program impacts) need to be assessed as well as traditional distal or final outcomes (Hollister \& Hill, 1995; Steckler et al., 1995). For example, community initiatives often describe “community change” as a stated goal of their initiative but usually only collect outcome data at the individual or dyadic level (e.g., marital breakups and participant satisfaction) (McKinlay, 1996). In addition to the obvious community-level outcomes of changes in marriage and divorce rates, other community change questions related to marriage could be: Did the community build the capacity to mobilize effective initiatives by forming coalitions across various sectors of the community to support marriage? To what extent was the “culture of marriage” developed in businesses, churches, and governmental organizations within the community? What affect did the community initiative have on the laws that govern the community or the state in which it resides?

In addition to broadening the array of distal outcomes, short term, intermediate outcomes can be assessed. Examples of intermediate outcomes that could be measured in community marriage initiatives are: What percentage of churches in the community signed CMPs or MFAs? How many couples were enrolled in marriage education and enrichment classes? How many mentor couples were trained, how many couples were mentored, and what was the experience of the participants in the mentor programs? These intermediate outcomes would add to an understanding of traditional (distal) program outcomes. For example, the evaluation of Marriage Savers’ impact on community divorce rates is hampered by a lack of data on intermediate outcomes; little is known 
about how many churches follow through on the Community Marriage Policies and how many couples participate in mentoring initiatives (Birch, Weed \& Olsen, this issue).

Finally, it is important that outcome data be collected on multiple levels that include individual, interpersonal, organizational, and community indicators of success. This will enable stakeholders and the community to better understand the impact the initiatives are making throughout the community (Goodman, 1998; Israel et al., 1995). For more information on specific outcome evaluation design strategies and models, see Dion et al., 2003; the Lewin Group, 1996; Rossi et al., 1999; Royse et al., 2001 and the United Way, 1996.

Lessons Learned from Evaluating Community Initiatives: Examples from the Literature

Although community marriage initiatives are proliferating across the country, and some are beginning to receive government and foundation support, little is known about their effectiveness or the challenges faced when trying to implement them. Two examples, one from Responsible Fatherhood programs and the other from health education programs, serve as examples of the issues faced when evaluating community interventions.

In the mid-90s the department of Health and Human Services and the Ford Foundation funded the Lewin Group and Johns Hopkins University to determine the readiness of Responsible Fatherhood programs to undergo comprehensive evaluation. In general, the report found that several criteria needed to be met before a comprehensive evaluation could be conducted: (a) programs had to clearly define the services they offered and be able to link those services to hypothesized outcomes that were clear and measurable; (b) programs needed to understand the context in which they were working, 
that is, the characteristics of the individuals and communities in which they intervened; (c) programs needed to be able to reach the target population and have established recruitment methods; (d) programs had to be able to track the participation rates and outcomes of the individuals in the programs; and (e) programs needed a sufficient number of participants to have adequate statistical power for data analysis (Lewin Group, 1996).

Rarely will experimental designs with randomization of communities be feasible in the work of community marriage initiatives. Churches band together to adopt a CMP or sign a MFA because they want to be involved in strengthening marriages. Recruiting communities to engage in a community wide initiative and then randomly assigning some of those communities to a control group is implausible. Over the last twenty years there have been several community health education interventions that for many reasons were unable to randomly assign communities (Fortmann et al., 1995; Mittelmark et al., 1993; Murray, 1995). The most generally used alternative to random assignment of communities is matching communities on known characteristics, conducting the community intervention in the targeted community, and then comparing changes in the outcome measures of interest. Lessons learned from community health initiatives using this design can inform the evaluation of community marriage initiatives. We rely especially on the work of Fortmann et al. (1995) and Murray (1995).

First, matching cities based on census and other available community data may not include enough characteristics specific to the social problem (e.g., coronary disease risk or divorce) to create an adequate community match. Communities matched on the best available data often turned out to be substantially different on important behavioral 
measures. Second, the magnitude (rate of increase or decrease) of secular trends in social problems such as cardiovascular risk factors or divorce may make it difficult for any intervention to accelerate or decelerate the trend. Third, it is often difficult to reach large portions of the target population with equal intensity in a community initiative. Interventions are often conceived at multiple levels. A community wide public educational campaign that includes PSAs and uses newspapers, TV, and radio will not reach all citizens since not everyone has access to these mediums. In addition these messages usually are not enough by themselves to promote behavior change. The interventions that more readily lead to direct behavior change (such as empirically supported programs and curricula) are often time-intensive and less likely to reach a significant portion of the eligible members of the community. This happens for a variety of reasons but can include underfunding for adequate staff to implement and disseminate the programs as well as the inherent difficulty in recruiting large sections of the population for time intensive education and programming. This dilutes the treatment effect because a substantial portion of the population does not receive the intervention. Finally, statistical power is low unless there are a large number of matched communities (Fortmann et al., 1995; Murray, 1995).

New alternatives are emerging to deal with the challenges of matching communities for purposes of evaluation. Fortmann et al. (1995) and Murray (1995) recommend detailed process evaluation with a special focus on institutional and organizational changes. For example, if far more health care facilities in the target community implemented smoking cessation programs, and if far more people in this community participate in smoking cessation programs than in the comparison 
community, then it is more plausible to assume that the intervention made a difference if the two communities experience different levels of decline in smoking rates. This will allow evaluators to measure outcomes and to use methods that are less likely to be influenced by secular trends (such as a widespread but temporary increase in attempts to quit smoking in both communities after a famous athlete dies of lung cancer) that can make data interpretation impossible.

Another new alternative is the use of interrupted time-series experiments in community interventions. As described by Biglan, Ary, and Wagenaar (2000), this approach typically involves several communities that are repeatedly assessed, with the introduction of the intervention into the "point” communities at a particular time. The slope of the data from the repeated assessments can be compared between communities with techniques for analysis of time series data. Here is a simplified example: if community A and community B both have averaged a decline of one percent per year in divorce rates over the past five years, and then community A introduced a CMP, it is possible to compare what happens to divorce rates in subsequent years in the two communities. If community B continues its one percent decline per year and community A increases its decline to two percent per year, then an inference can be made (although not definitely proved) that the intervention may have caused the difference, especially if a lot is known about the process and intermediate outcomes of the intervention. Ideally there are at least several communities in the intervention group and the matched comparison group. And repeating such time series experiments with multiple diverse communities would add confidence to the causal inferences. This is the procedure being used to evaluate the impact of Marriage Savers Community Marriage Policies, in which 
the evaluators are matching communities based on similar slopes of divorce rate changes prior to the intervention, and then comparing the directions of the slopes in the years following the introduction of the intervention (Birch, Weed, \& Olsen, this issue).

\section{Innovative Directions}

In addition to recommendations for process and outcome evaluation discussed in the previous section, we suggest that community marriage initiatives lend themselves well to action research methods and to community organizing models. Action research (sometimes called Participatory Action Research) is a decades-old evaluation strategy and form of social inquiry that involves active partnership and collaboration between researchers and participants in a way that minimizes hierarchy and engages participants in the research and evaluation process (Reason \& Bradbury, 2001). The goals of action research are to create knowledge and bring about social change (Greenwood \& Levin, 1998). Action research involves a cyclical process of democratic action and reflection, in which (a) a problem is identified and information is gathered regarding it, (b) solutions to address the problem are developed and refined, (c) interventions are implemented, and (d) outcomes are evaluated and the intervention is modified (if indicated) in light of new information obtained in steps $1-3$. Action research is generally a slow and cumbersome process, especially during initial phases of development, but it offers unique opportunities for involving community stakeholders in the development and evaluation of interventions, and thus for the endurance of the changes that were implemented.

In a new community project for which we recently received a federal grant, we are using action research in combination with a community organizing model called "The Families and Democracy Model” (Doherty \& Carroll, 2002b). This model redefines the 
role of the family professional as a catalytic leader with communities of families. It seeks to mobilize families as primary stakeholders in promoting community well being and cohesiveness. In this approach, professional programs become options available to an activated community of families, rather than the driving vehicle of family improvement. Families and Democracy projects also aim for public visibility in order to influence broader cultural change.

The combined use of action research and Families and Democracy models require a three-step process to implement a project: 1) assembling the stakeholders, 2) creating a leadership and decision making team that involves both researchers and community members, and 3) decisions on how to implement and evaluate the project. In this approach, professional expertise is important but as a resource "on tap,” not "on top.” Our newly funded community project will work with unmarried new parents in an urban, high-risk community, combining intensive process evaluation (which action research generally utilizes) and more traditional outcome assessment. The plan involves first consulting with the "experts” on successful family formation among urban, unmarried new parents—namely, those who have done it. We will locate couples in a large urban community who started out as unmarried new parents (so called “fragile families”) and who are now successfully married and raising their child together. We will interview them individually and in focus groups to learn how they defeated the odds by forming and sustaining a healthy marriage and family. We will then recruit some of these couples as mentors to the next generation and as co-leaders in the project. We will also engage faith communities and other community groups in urban and suburban neighborhoods to provide additional mentoring and support for the unmarried new 
parents we recruit, and to serve on the leadership team for the project. Representative marriage educators, parent educators, and marriage and family therapists will also be part of the leadership group, together with University researchers. Services in addition to mentoring will be made available to couples as the project unfolds rather than being determined at the outset. It is expected that some of the couples that join the project as unmarried new parents will be invited to become mentors themselves as they mature in their marriages. Finally, the project will actively engage civic leaders and the media in public events to showcase the successful efforts of couples in the project, with the larger goal of counteracting the culture of despair about the prospects of unmarried new parents in our urban communities. All of these strategies reflect community organizing principles in which traditional marriage education approaches are built in after the community is organized rather than determined in advance by professionals.

In conclusion, the first decade of the $21^{\text {st }}$ century presents unique opportunities for professional/community partnerships in developing and evaluating community marriage initiatives. Although promising, this is difficult work, with standards still being developed. Current community initiatives are still in their infancy when it comes to evaluation of process and outcome, but we are witnessing a convergence of communitygenerated efforts, faith-based initiatives, and professionally developed programs. The new learnings from this rapprochement can enrich the field of family science by extending its borders into new territory, and add substantially to our understanding of how social, cultural, and community forces can be mobilized to improve the quality of marriage and family life. 


\section{References}

Biglan, A., Ary, D. V., \& Wagenaar, A. C. (2000). The value of interrupted time-series experiments for community intervention research. Prevention Research, 1, 31-49.

Birch, P., Weed, S., \& Olsen, J. (this issue). Assessing the impact of community marriage policies on U.S. county divorce rates. Family Relations.

Blaisure, K., \& Allen, K. (1995). Feminists and the ideology and practice of marital equality. Journal of Marriage and Family, 57, 5-19.

Browning, D. S., Miller-McLemore, B. J., Couture, P. D., Lyon, K. B., \& Franklin, R. M. (2000). From culture wars to common ground ( $2^{\text {nd }}$ ed.). Louisville, KY: Westminster.

Cavedo, C., \& Guerney, B. G. (1999). Relationship enhancement and problemprevention programs: Therapy-driven, powerful, versatile. In R. Berger \& M. T. Hannah (Eds.), Preventive approaches in couples therapy (pp. 73-105). New York: Brunner/Mazel.

Cohen, L. (2003). A consumer's republic: The politics of mass consumption in post war America. New York: Knopf.

Dion, M. R., Devaney, B., McConnell, S., Ford, M., Hill, H., \& Winston, P. (2003). Helping unwed parents build strong and healthy marriages: A conceptual framework for interventions (Contract No. 282-98-0021 22). Washington, DC: Mathematica Policy Research, Inc.

Doherty, W. J., \& Carroll, J. S. (2002a). Health and the ethics of marital therapy and education. In J. Wall, D. Browning, W. J. Doherty, \& S. Post (Eds.), Marriage, health, and the professions (pp. 208-232). Grand Rapids, MI: Eerdsman. 
Doherty, W. J., \& Carroll, J. S. (2002b). The families and democracy project. Family Process 41, 579-589.

Elin, R. J., (1999). Marriage Encounter: A positive preventive enrichment program. In R. Berger \& M. T. Hannah (Eds.), Preventive approaches in couples therapy (pp. 55-72). New York: Brunner/Mazel.

Families Northwest. (n.d.). Community strategies. Retrieved July 17, 2003, from http://www.familiesnorthwest.org/marriage_strategies.cfm

Fancher, R. T. (1995). Cultures of healing: Correcting the image of American mental health care. New York: W. H. Freeman.

First Things First. (n.d.a). What is first things first? Retrieved July 17, 2003, from http://www.firstthings.org/green/whatis.html

First Things First. (n.d.b). Statistics: Facts about marriage and divorce. Retrieved July 17, 2003, from http://www.firstthings.org/blue/marriage_stats.html

Franklin, R. E. (in press). Where’s dad? Fatherhood in African American communities. In J. Witte (Ed.), Marriage, family, and the religions of the book. Grand Rapids, MI: Eerdsman.

Fortmann, S. P., Flora, J. A., Winkleby, M. A., Schooler, C., Taylor, C. B., \& Farquhar, J. W. (1995). Community intervention trials: Reflections on the Stanford five-city project experience. American Journal of Epidemiology, 142, 576-586.

Goodman, R. M. (1998). Principles and tools for evaluating community-based prevention and health promotion programs. Journal of Public Health Management Practice, 4, 37-47. 
Gordon, L. H., \& Durana, C. (1999). The PAIRS program. In R. Berger \& M. T. Hannah (Eds.), Preventive approaches in couples therapy (pp. 217-254). New York: Brunner/Mazel.

Greenwood, D. J., \& Levin, M. (1998). Introduction to action research. Newbury Park, CA: Sage.

Halford, W. K., Markman, H. J., Kline, G. H., \& Stanley, S. M. (2003). Best practices in couples education. Journal of Marital and Family Therapy, 29, 385-406.

Healthy Marriages Grand Rapids. (n.d.a). All about healthy marriages Grand Rapids. Retrieved July 17, 2003, from http://www.healthymarriagesgr.org/aboutggrcmp/ ggrcmp_policy.htm

Healthy Marriages Grand Rapids. (n.d.b). Accomplishments to date. Retrieved July 17, 2003, from http://www.healthymarriagesgr.org/aboutggrcmp/accomplishments\% 20to\%20date.pdf

Healthy Marriages Grand Rapids. (2003). Three organizations in west Michigan will use federal grant of \$990,000 to develop a child support demonstration project. Retrieved July 17, 2003, from http://www.healthymarriagesgr.org/images/ grant\%20PR.pdf

Hollister, R. G., \& Hill, J. (1995). Problems in the evaluation of community-wide initiatives. In J. P. Connell, A. C. Kubisch, L. B. Schorr, \& C. H. Weiss (Eds.), New approaches to evaluating community initiatives: Concepts, methods, and contexts (pp. 127-172). Washington, DC: The Aspen Institute.

Israel, B. A., Cummings, K. M., Dignan, M. B., Heaney, C. A., Perales, D. P., Simons- 
Morton, B. G., et al. (1995). Evaluation of health education programs: Current assessment and future directions. Health Education Quarterly, 22, 364-389.

Johnson, C. A., Stanley, S. M., Glenn, N. D., Amato, P. R., Nock, S. L., Markman, H. J., et al. (2002). Marriage in Oklahoma: 2001 baseline statewide survey on marriage and divorce. Oklahoma City, OK: Oklahoma Department of Human Services.

Krafsky, K. J. (n.d.). The northwest marriage and family movement: Strategy blueprints for families northwest's ten-year cultural campaign. Retrieved July 17, 2003, from Families Northwest Web site: http://www.familiesnorthwest.org/pdf/ nwmfm_strategyblueprints.pdf

Lester, M. E., \& Doherty, W. J. (1983). Couples' long term evaluations of their Marriage Encounter experience. Journal of Marital and Family Therapy, 9, 183-188.

The Lewin Group, Inc. (1997, August 6). An evaluability assessment of responsible fatherhood programs. Retrieved July 31, 2003, from http://fatherhood.hhs.gov/ evaluaby/intro.htm

Mace D. (1983). Close companions: The marriage enrichment handbook. New York: Continuum Publishing Group.

Markman, H., Stanley, S., \& Blumberg, S. L. (1994). Fighting for your marriage: Positive steps for preventing divorce and preserving a lasting love. San Francisco: Jossey-Bass.

Marriage Savers (n.d.). About marriage savers. Retrieved July 17, 2003, from http://marriagesavers.org/aboutmarriagesavers.htm McGraw, S. A., Stone, E. J., Osganian, S. K., Elder, J. P., Perry, C. L., Johnson, C. C., et 
al. (1994). Design and process evaluation within the child and adolescent trial for cardiovascular health (CATCH). Health Education Quarterly, 21(Suppl. 2), S5S26.

McKinlay, J. B. (1996). More appropriate evaluation methods for community-level health interventions. Evaluation Review, 20, 237-243.

McManus, M. J. (1995). Marriage savers. Grand Rapids, MI: Zondervan.

McManus, M. J. (2002). Marriage savers annual report. Retrieved July 17, 2003, from Marriage Savers Web site: http://www.marriagesavers.org/Annual\%20Report.htm

McManus, M. J. (2003a). Ten steps to create a community marriage policy/covenant. Retrieved July 17, 2003, from http://marriagesavers.org/public/10_steps.htm

McManus, M. J. (2003b). How churches can rebuild troubled marriages. Retrieved July 17, 2003, from Marriage Savers Web site: http://www.marriagesavers.org/public/ saving.htm

Miller, S., \& Sherrard, P. A. D. (1999). Couple Communication: A system for equipping partners to talk, listen, and resolve conflicts effectively. In R. Berger \& M. T. Hannah (Eds.), Preventive approaches in couples therapy (pp. 125-148). New York: Brunner/Mazel.

Mittelmark, M. B., Hunt, M. K., Heath, G. W., \& Schmid, T. L. (1993). Realistic outcomes: Lessons learned from community-based research and demonstration programs for the prevention of cardiovascular diseases. Journal of Public Health Policy, 14, 437-462.

Murphy, C. (2000, November 15). Clergy call for bolstering marriage. The Washington Post, pp. A6. 
Murray, D. M. (1995). Design and analysis of community trials: Lessons learned from the Minnesota heart health program. American Journal of Epidemiology, 142, 569-575.

Oklahoma Marriage Initiative. (n.d.a). OMI history. Retrieved March 25, 2004, from http://www.okmarriage.org/ProgramHighlights/MarriageProblems.asp

Oklahoma Marriage Initiative. (n.d.b). Service delivery system. Retrieved March 25, 2004, from http://www.okmarriage.org/TrainingInstitute/ContinuingEducation. asp

Olson, D. H., \& Olson, A. K. (1999). PREPARE/ENRICH program: Version 2000. In R. Berger \& M. T. Hannah (Eds.), Preventive approaches in couples therapy (pp. 196-216). New York: Brunner/Mazel.

Pinsof, W. M. (2002). The death of "till death to us part": The transformation of pairbonding in the $20^{\text {th }}$ century. Family Process, 41 , 135-157.

Reason, P., \& Bradbury, H. (Eds.). (2001). Handbook of action research: Participative inquiry and practice. London: Sage.

Rossi, P. H., Freeman, H. E., \& Lipsey, M. W. (1999). Evaluation: A systemic approach (6 $6^{\text {th }}$ ed.). Thousand Oaks, CA: Sage.

Royse, D., Thyer, B. A., Padgett, D. K., \& Logan, T. K. (2001). Program evaluation: An introduction ( $3^{\text {rd }}$ ed.). Belmont, CA: Wadsworth.

Shumway, S. T., Wampler, R. S., Dersch, C., \& Arredondo, R., (2004). A place for marriage and family therapy services in employee assistance programs (EAPs): A survey of EAP client problems and needs. Journal of Martial and Family Therapy, 30, 71-79. 
Stacey, J. (1990). Brave new families. New York: Basic Books.

Stanley, S. M., Blumberg, S. L., \& Markman, H. J. (1999). Helping couples fight for their marriages: The PREP approach. In R. Berger and M. T. Hannah (Eds.) Preventive approaches in couples therapy (pp. 279-303). New York: Brunner/Mazel.

Stanley, S. M., Markman, H. J., Prado, L. M., Olmos-Gallo, P. A., Tonelli, L., St. Peters, M., et al. (2001). Community-based premarital prevention: Clergy and lay leaders on the front lines. Family Relations, 50, 67-76.

Stanley, S. M., Markman, H. J., St. Peters, M., \& Leber, D. (1995). Strengthening marriages and preventing divorce: New directions in prevention research. Family Relations, 44, 392-401.

Steckler, A., Allegrante, J. P., Altman, D., Brown, R., Burdine, J. N., Goodman, R. M., et al. (1995). Health education intervention strategies: Recommendations for future research. Health Education Quarterly, 22, 307-328.

United Way of America (1996). Measuring program outcomes: A practical approach. Alexandria, VA: Author.

Whitehead, B. D. (1993, April). Dan Quayle was right. Atlantic Monthly. Retrieved September 29, 2003, from http://www.theatlantic.com/politics/family/ danquayl.htm 